\title{
A filosofia na reforma curricular do Ensino Médio pós LDB: habilidades e competências na formação para a cidadania
}

\author{
Altair Alberto Fávero' \\ Ana Lucia Kapczynski²
}

\begin{abstract}
Resumo
A necessidade de caracterizar a filosofia como disciplina escolar motivou esta pesquisa documental em torno do planejamento curricular, com enfoque na seleção dos conteúdos mínimos para a base nacional comum. Nosso objetivo é compreender as diretrizes para o ensino de filosofia previsto pela reforma curricular no Ensino Médio em contextos de transição da formação instrumental científico-tecnológica, de caráter elitista e propedêutico, para a formação cidadã baseada nos ideais de humanismo e diversidade. Para tanto nos baseamos especificamente nos Parâmetros Curriculares Nacionais de 1999. Nesse período entrou em cena a universalização do Ensino Médio com a proposta de formação geral em substituição à educação técnica por especialidades. Priorizou-se o desenvolvimento de habilidades e competências em quatro grandes áreas, incluindo as linguagens e seus códigos, os conhecimentos de matemática e as ciências Naturais e Humanas. A flexibilidade e a contextualização elevaram a seleção dos conteúdos ao segundo plano, relegando à filosofia o caráter interdisciplinar para o diálogo com a ciência e a tecnologia, ao desenvolvimento da leitura, da problematização, da análise e da escrita a partir das dimensões ética (identidade autônoma), estética (sensibilidade) e política (equidade e democracia).
\end{abstract}

Palavras chaves: ensino de filosofia; formação; cidadania.

1 Pós-Doutorado (Bolsista Capes) pela Universidad Autónoma del Estado de México (UAEMéx), Doutorado em Educação (UFRGS), Mestre em Filosofia do Conhecimento (Pucrs), Especialista em Epistemologia das Ciências Sociais (UPF) e Graduado em Filosofia (UPF). Atua como professor e pesquisador no Curso de Filosofia, no Mestrado e Doutorado em Educação da Universidade de Passo Fundo/RS/Brasil. É coordenador do projeto "Docência Universitária, Políticas Educacionais e Expansão da Educação Superior: limites e possibilidades" desenvolvido junto ao PPGED da UPF.E-mail: altairfavero@gmail.com

2 Mestranda em Educação (Universidade de Passo Fundo/UPF/RS/Brasil), Bacharel em Filosofia pelo Instituto de Filosofia Berthier (IFIBE) e licenciada em Filosofia pela Universidade de Passo Fundo (UPF). Atua como professora da Educação Infantil da Rede Municipal de Passo Fundo e é integrante do grupo de Pesquisa "Docência Universitária, Políticas Educacionais e Expansão da Educação Superior: limites e possibilidades", desenvolvido junto ao PPGEDU da UPF. E-mail: anakapczynski@gmail.com 


\title{
The philosophy in education curriculum reform after LDB: skills and expertise in training for citizenship
}

\begin{abstract}
The necessity of characterize philosophy as school discipline motivated this documentary research around curriculum planning, focusing on the selection of minimum contents for the common national basis. Our goal is to understand the guidelines for teaching philosophy provided by the curriculum reform in high school in contexts of transition from scientific and technological instrumental training, elitist and introductory character, to civic education based on ideals of humanism and diversity. For this, we rely specifically on the 1999 National Curriculum Parameters. During this period came on the scene the universalization of High School with the purpose of general education in place of technical education by specialties. The development of skills and competences are prioritized into four major areas, including the languages and their codes, math skills and the Natural and Human Sciences. The flexibility and contextualization increased the selection of contents to second place, relegating the philosophy interdisciplinary character for dialogue with science and technology, development of reading, questioning, analyzing and writing from the ethical dimensions (autonomous identity), aesthetic (sensitivity) and politics (equity and democracy).
\end{abstract}

Keywords: philosophy of education; formation; citizenship.

\section{Considerações Iniciais}

A virada do século XX para o século XXI foi movida por profundas mudanças decorrentes do avanço científico e tecnológico que interferiu no cotidiano das pessoas e consequentemente, na organização escolar. Com a Lei de Diretrizes e Bases 9.394/96, o Ensino Médio passou a ser parte da Educação Básica, donde surgem os Parâmetros Curriculares Nacionais para auxiliar o trabalho docente. A modalidade de ensino descontextualizado, compartimentalizado e baseado no acúmulo de informações dá lugar à proposta curricular contextualizada e significativa ao conhecimento escolar, com atividades interdisciplinares pautadas no desenvolvimento de competências voltadas às habilidades de raciocínio e na capacidade de aprender.

Substitutivo do antigo Segundo Grau, o Ensino Médio objetivou relacionar a teoria com a prática, propondo um estilo de formação alicerçada na aquisição de conhecimentos básicos, na preparação científica e na capacidade de utilizar as diferentes tecnologias relativas às áreas de atuação. Sobretudo a informática promoveu mudanças radicais na área do conhecimento, interferindo na compreensão teórica sobre o papel da escola em decorrência da incorporação 
das novas tecnologias. Surge, então, a proposta de reforma curricular para o Ensino Médio, regulada pelas mudanças ocorridas no âmbito do conhecimento tanto em seus desdobramentos na produção quanto nas relações sociais de modo geral.

Enquanto nas décadas de 1960 e 1970 as políticas educacionais priorizaram a formação de especialistas capazes de manusear maquinarias e dirigir processos de produção na indústria, na década de 90 o desafio para o Ensino Médio foi de outra ordem, de pensar a educação considerando o volume de informações produzido pelas tecnologias. A transposição de conhecimentos deixou de ser uma estratégia eficaz para a formação secundária para dar lugar à produção de saberes, o exercício de memorização ao desenvolvimento das capacidades de análise, investigação e criação e a formação específica foi suprida pela formação geral.

A reforma curricular direcionou o desenvolvimento dos conteúdos por áreas do conhecimento numa perspectiva de interdisciplinaridade e contextualização e não mais por meio de disciplinas isoladas. O paradigma de instrumentalização da formação profissional perdeu relevância no Ensino Médio para a centralidade no desenvolvimento de competências exigidas para o exercício da cidadania e autonomia na produção de conhecimentos.

Expressar a contemporaneidade tornou-se o foco da concepção curricular na década de 90, enquanto prospectiva das tendências apontadas para o século $X X I$, de possibilidades de intervenção em áreas inexploradas como a biogenética e a robótica. Previa-se no século XXI a diminuição de oportunidades para o trabalho não qualificado e a necessidade de atualização do conhecimento frente à velocidade do progresso científico e tecnológico. A revolução tecnológica globalizada sinalizava mudanças no campo da socialização e das concepções identitárias individuais e coletivas, incidindo sobre as questões éticas, estéticas e políticas.

Partindo das realidades simbólicas relativas ao trabalho e à constituição de sujeitos ativos que se apropriam dos conhecimentos para se aprimorar, a organização curricular do Ensino Médio rompeu com os modelos tradicionais na perspectiva de uma aprendizagem permanente, de formação continuada tendo a 
cidadania como elemento central em virtude da modificação dos processos sociais.

Objetivando compreender as diretrizes da legislação sobre os critérios de seleção de conteúdos para a base nacional comum dos currículos de filosofia no Ensino Médio, partimos de uma pesquisa documental com a finalidade de analisar as orientações dos documentos oficiais sobre o planejamento curricular. Nesse sentido, no primeiro tópico resgatamos o percurso histórico da filosofia no Ensino Médio, centrado na reforma curricular oriunda da nova concepção de educação, que demarcou a transição do século XX ao século XXI. Em seguida apresentamos panoramicamente os principais pilares das Diretrizes Curriculares para o Ensino Médio com a intenção demostrar que a ética, a estética e a política aparecem em tal documento como fundamentos da Educação Básica (terceiro tópico). Por fim, nas considerações finais fazemos um balanço de como se apresenta o ensino de filosofia neste contexto pós LDB 9394/1996.

\section{A reforma curricular no horizonte das inovaçōes científicas e tecnológicas}

Os conteúdos e as estratégias de aprendizagem, propostos pela reforma curricular na década de 1990, partem de três domínios da ação humana: a vida em sociedade, a atividade produtiva e a experiência subjetiva, tendo em vista as relações políticas, de trabalho e o mundo simbólico. Incorporam-se como diretrizes o aprendizado em torno do conhecimento (teórico), do fazer (prático), do viver (socialização) e do ser (autonomia), em que o desenvolvimento integral da pessoa supunha exercitar a liberdade de pensamento, o discernimento, a imaginação e os afetos.

De acordo com a reforma curricular, a seleção de conteúdos deveria partir dos eixos histórico-cultural e epistemológico, de modo a submeter o currículo à prova de validade, relevância social e à reconstrução dos procedimentos envolvidos na produção do conhecimento. Desde então estava prevista a Base Nacional Comum de preparação para o prosseguimento dos estudos no sentido de desenvolvimento de competências e habilidades básicas e não no acúmulo de esquemas resolutivos pré-estabelecidos. 
A dimensão da preparação para o trabalho aparecia com maior ênfase no PCN de 1999 enquanto instrumento de solução de problemas concretos como o domínio da linguagem culta e dos conhecimentos de matemática. Destinada à formação geral, a Base Nacional Comum tinha por finalidade a construção de competências com vistas ao desenvolvimento de habilidades básicas, técnicas ou de gestão, requeridas no exercício profissional, seja psicomotora, socioafetiva ou cognitiva.

O conceito de democratização e flexibilidade aparece neste PCN ainda num cenário de formação propositiva em termos de conteúdos e metodologias que precisam estar alinhados com a legislação. "A definição destas competências e habilidades servirá de parâmetro para a avaliação da Educação Básica em nível nacional" (BRASIL, 1999, p. 31). Por outro lado, a legislação orienta que a organização curricular esteja comprometida com as mudanças econômicas e sociais. Com base na LDB, destaca-se como diretrizes curriculares para o Ensino Médio o planejamento e o desenvolvimento do currículo de forma orgânica, revigorando a integração e articulação dos conhecimentos e superando a organização curricular por disciplinas estanques.

Ressalve-se que uma base curricular nacional organizada por áreas de
conhecimento não implica a desconsideração e o esvaziamento dos
conteúdos, mas a seleção e integração dos que são válidos para o
desenvolvimento pessoal e para o incremento da participação social.
Essa concepção curricular não elimina o ensino de conteúdos
específicos, mas considera que os mesmos devem fazer parte de um
processo global com várias dimensões articuladas (BRASIL, 1999, p. 32).

A interdisciplinaridade e a transdisciplinaridade são requisitadas pela LDB de 1996, no artigo 36, no domínio dos princípios científicos e tecnológicos, das linguagens contemporâneas e dos conhecimentos de filosofia e sociologia necessários ao exercício da cidadania, complementando o artigo 35 que trata das finalidades do Ensino Médio. Compondo a etapa final da Educação Básica, a formação secundária visa consolidar e aprofundar os conhecimentos adquiridos no Ensino Fundamental como aporte ao prosseguimento dos estudos, preparação básica para o trabalho e formação cidadã. Parte da formação ética, do desenvolvimento da autonomia intelectual e do pensamento crítico, com vistas a ampliar a capacidade de relacionar a teoria com a prática pela compreensão dos 
fundamentos científicos e tecnológicos dos processos educativos (BRASIL, 1999, p. 31).

\section{As Diretrizes Curriculares para o Ensino Médio no final da década de 1990}

A autonomia das escolas no planejamento curricular foi a grande revolução que a Lei de Diretrizes e Bases $9.394 / 96$ provocou na educação formal, especialmente no novo olhar atribuído ao Ensino Médio que passou a compor a última etapa da Educação Básica numa proposta curricular de formação geral sem a dimensão específica da profissionalização e da preparação para o Ensino Superior. O cumprimento da função legal da LDB de regulamentar a base curricular nacional e organizar o Ensino Médio partiu do Aviso n 307, de 07/07/97, encaminhado pelo Ministro da Educação e do Desporto para apreciação e deliberação da Câmara de Educação Básica (CEB) do Conselho Nacional de Educação (CNE). O documento ministerial procedeu do Ministério da Educação (MEC) por intermédio da Secretaria de Ensino Médio e Tecnológico (SEMTEC), baseado em consultas a variadas vertentes (BRASIL, 1999, p. 59)

A formulação das Diretrizes Curriculares Nacionais resultou de estudos que enfatizaram três aspectos: o conceito de diretrizes adotado pela legislação, o papel do Conselho Nacional de Educação e os princípios éticos, políticos e estéticos que inspiraram a LDB, com ênfase aos últimos princípios que delimitaram o marco legal. Além da contribuição das pessoas diretamente vinculadas aos espaços oficiais, a fundamentação teórica deste documento contou com a presença qualificada de entidades como a Associação de Pós-Graduação em Educação (ANPEd), a Confederação Nacional de Trabalhadores da Educação (CNTE), universidades públicas e privadas, associações de escolas particulares de Ensino Médio, as instituições do Sistema S (SENAI, SENAC, SENAR) e SEMTEC.

Em consonância com o artigo $9^{\circ}$ inciso IV da LDB, as Diretrizes Curriculares Nacionais de 1999 estabeleciam conteúdos mínimos aos currículos escolares, de modo a assegurar formação básica comum (BRASIL, 1999, p. 61). Contudo, a LDB não esclarece os critérios para a escolha destes conteúdos mínimos porque enfatiza a descentralização dos currículos escolares com vistas à autonomia pedagógica. 
Parece-nos haver um paradoxo na legislação entre a liberdade dos sistemas de ensino em organizar os currículos e a indicação de garantir uma base comum nacional de formação que contemplem conteúdos mínimos. Em contrapartida, a inexistência de propostas de conteúdos norteadores tende a contribuir para a descaracterização das áreas do conhecimento, permitindo o distanciamento de suas bases epistemológicas.

Outra questão diz respeito à proposta da inserção da filosofia na interdisciplinaridade. Questiona-se se há possibilidade de tratar seus temas sem o conhecimento dos conteúdos filosóficos, se é possível reduzir a filosofia a uma metodologia de ensinar a pensar, de que forma relacionar a autonomia das instituições educacionais em elaborar seus currículos com o domínio de conhecimentos exigidos ao final do Ensino Médio e as avaliações de qualidade da educação. Nesse sentido, incluindo a filosofia, os currículos da escola secundária entremeiam o âmago da tensão entre a descentralização e a necessidade de uma base nacional comum. Se a doutrinação revelou seus limites, a ausência de referenciais igualmente poderá acarretar em prejuízos pela fragmentação do saber construído ao longo da história. Ora, se o conhecimento não evolvi de modo linear, tampouco avançaria distanciado de seus fundamentos, do rigor metodológico necessário para alcançar níveis mais elevados de erudição. Essa prática seria um retorno ao senso comum, gerando novas formas de exclusão no Ensino Médio.

Visando superar a exclusão na etapa final da escolaridade recentemente tornada obrigatória, estas Diretrizes Curriculares Nacionais foram forjadas diante de transformações significativas no cenário econômico e político, de valorização da educação na qualificação profissional e na conquista de direitos da cidadania. 0 aumento da demanda tributou a composição de clientelas mais heterogêneas em termos de situação socioeconômica e faixa etária. De 1985 a 1994, o crescimento das matrículas no Ensino Médio superou em 100\%, concentradas em escolas públicas, predominantemente noturnas (BRASIL, 1999, p. 65).

Historicamente no Brasil o Ensino Médio manifestou seu caráter elitista de função propedêutica e profissionalizante até a universalização determinada pela LDB de 1996. Com isso, as escolas secundárias precisaram organizar currículos que atendessem clientelas de origens, destinos sociais e aspirações muito diferenciadas, 
tendo como finalidades consolidar e aprofundar os conhecimentos adquiridos no ensino fundamental para possibilitar o prosseguimento dos estudos, a preparação básica para o trabalho e a cidadania, a formação da pessoa humana nos aspectos da ética, da autonomia intelectual e do pensamento crítico. A filosofia é citada como necessária ao exercício da cidadania por sua capacidade de relacionar teoria e prática, a fim de facilitar a compreensão dos processos científicos e tecnológicos.

Ainda que a LDB de 1996 estabelecesse a formação geral para o ensino secundário, a lei admite a educação profissional e tecnológica em instituições especializadas. Os conteúdos previstos para a formação geral e a preparação para o prosseguimento nos estudos não se reduzem ao acúmulo de informações, mas ao desenvolvimento da capacidade de aprender e compreender o mundo físico, social e cultural. De acordo com o artigo 35 da LDB, entende-se por formação básica a preparação para todos os tipos de trabalho, tendo como referência as mutações nas demandas do mercado de trabalho, o que depende da disposição e da capacidade de aprendizagem. A relação da teoria com a prática deve partir da compreensão dos processos produtivos enquanto aplicação das ciências, em todos os conteúdos curriculares. "A preparação básica para o trabalho não está, portanto, vinculada a nenhum componente curricular em particular, pois o trabalho deixa de ser obrigação - ou privilégio - de conteúdos determinados para integrarse ao currículo como um todo" (BRASIL, 1999, p. 70).

Na perspectiva de relação entre a teoria e a prática, a legislação não explica o que deve direcionar a escolha dos conteúdos para atender as realidades locais, apontando para o risco de distanciar a proposta curricular dos fundamentos epistemológicos de cada área do saber. Permanece em aberto o questionamento sobre o conceito de formação geral, prevista para a Educação Básica, voltada à habilitação de profissionais para atender as demandas locais de mercado. Sem ter clareza quanto aos fundamentos da formação para a capacidade de continuar aprendendo, para a autonomia intelectual, para o pensamento crítico e saber interagir com as ciências, não estaríamos diante de uma polissemia em torno do conceito de verdade que poderá fragmentar o conhecimento a partir da ideia que 
"cada um possui a sua verdade", sem o comprometimento com o rigor científico necessário à produção do saber?

O problema de fundo é o entendimento do que vem a ser a base nacional comum que no artigo $9^{\circ}$ inciso IV da LDB prevê a definição de conteúdos mínimos enquanto nos artigos $8^{\circ}, 12^{\circ}$ e $15^{\circ}$ sugere a flexibilidade dos currículos a partir de expressões como "liberdade de organização", "os estabelecimentos de ensino terão a incumbência de elaborar e executar sua proposta pedagógica" e "autonomia pedagógica" (BRASIL, 1999, p. 41-42). Esse debate ganha complexidade quanto ao ensino de filosofia na transversalidade sem menção aos conteúdos básicos, restringindo-o a uma prática de formação.

Quais seriam as expectativas expressas na legislação em torno da contribuição da filosofia para a formação cidadã, tomando por base as competências de linguagens e das ciências exatas, naturais e humanas? Em linhas gerais aparecem alguns indicativos como a criatividade, autonomia e capacidade de solucionar problemas em contextos afetados pelas mudanças nas formas de conviver, de exercer a cidadania e de organizar o trabalho. Frente à ameaça de fragmentação e segmentação num período histórico em que o Ensino Médio foi reformulado pelo forte anseio de inclusão e de integração social, a sociologia entra nos currículos escolares como ciência voltada à afirmação dos direitos da cidadania e compreensão dos fenômenos sociais em transformação acelerada, enquanto a filosofia ingressa como aporte de diálogo entre as diferentes áreas do saber e como recurso para a autonomia intelectual e pensamento crítico.

Como visto anteriormente, as alterações de paradigmas no conhecimento, na produção e no exercício da cidadania moveram a obrigatoriedade do Ensino Médio, uma etapa da escolaridade considerada elitista até o momento e que tradicionalmente acumulou as funções propedêuticas e de terminalidade. O PCN explicita que o objetivo principal da reforma curricular na década de 1990 consistiu nas mudanças econômicas e tecnológicas. Esta reforma apresentou duas características peculiares: "[...] progressiva integração curricular e institucional entre as várias modalidades da etapa de escolaridade média; e visível desespecialização das modalidades profissionalizantes" (BRASIL, 1999, p. 71). 
Contudo, outros elementos foram incorporados à reforma curricular e superaram a subordinação do Ensino Médio às necessidades da economia como os ideais do humanismo e da diversidade. O relatório da UNESCO da Reunião Internacional sobre Educação para o Século XXI determinou quatro grandes necessidades de aprendizagem indissociáveis para a formação humana de caráter integral: aprender a conhecer, aprender a fazer, aprender a conviver e aprender a ser. Nesse cenário, destacam-se as teorias que valorizam os afetos e a criatividade no ato de aprender. "A integração das cognições com as demais dimensões da personalidade é o desafio que as tarefas de vida na sociedade da informação e do conhecimento estão (re)pondo à educação e à escola" (BRASIL, 1999, p. 72).

A reposição do humanismo nas reformas do Ensino Médio é reivindicada como resposta aos possíveis efeitos negativos da pós-industrialização e da fragmentação gerada pela quantidade de informações e pela velocidade com que são veiculadas. Diante dessa nova conjuntura, espera-se que a escola contribua para o protagonismo responsável no exercício da cidadania e na relação estabelecida com o conhecimento e as informações.

A homologação da LDB em 1996 foi vista com entusiasmo no contexto de possibilidades acenadas pela situação brasileira, pois suas diretrizes e bases estavam em sintonia com a última geração de reformas da educação secundária no mundo e com as demandas educacionais contemporâneas, buscando conciliar humanismo e tecnologia. Mais que o cumprimento burocrático dos mandamentos legais, "[...] a LDB é uma convocação que oferece à criatividade e ao empenho dos sistemas e suas escolas a possibilidade de múltiplos arranjos institucionais e curriculares inovadores" (BRASIL, 1999, p, 73).

Transparece na LDB 9.394/96 a convocação da sociedade pela afirmação do Estado democrático, os ideais de libertação que sucederam ao recente rompimento com o sistema autoritário da Ditadura Militar no Brasil e na América Latina, o que justifica a comemoração da conquista de um direito promissor na diminuição das desigualdades sociais. A legislação balizou um marco de maior justiça, igualdade, fraternidade e felicidade. 


\section{Os fundamentos da Educação Básica: a ética, a estética e a política}

Quando trata dos fundamentos estéticos, políticos e éticos do Ensino Médio, as Diretrizes Curriculares Nacionais de 1999 buscam na filosofia suas bases teóricas, reconhecendo as especificidades desta área do saber no estabelecimento do plano axiológico, reportando-se à filosofia grega de Sócrates e Platão. Sugerem como critérios de organização curricular a sensibilidade, a igualdade e a identidade a partir dos fundamentos que pretendem integrar as áreas do saber conciliando humanismo e tecnologia. A estética da sensibilidade visa substituir a repetição e a padronização hegemônica herdada da era industrial e estimular a criatividade, a curiosidade pelo inusitado e a afetividade para facilitar o reconhecimento e a valorização da diversidade. Todavia, a estética da sensibilidade não deve abdicar de dar significado universal aos conteúdos da aprendizagem, valorizando a qualidade e 0 aprimoramento permanente. Associada às dimensões éticas e políticas, deve "[...] promover a crítica à vulgarização da pessoa; às formas estereotipadas e reducionistas de expressar a realidade; às manifestações que banalizam os afetos e brutalizam as relações pessoais" (BRASIL, 1999, p, 79, grifos nossos).

Harmonizada com a estética da sensibilidade que objetiva superar a exclusão, a intolerância e a intransigência, a política da igualdade parte do reconhecimento dos direitos humanos e do exercício dos direitos e deveres da cidadania, do princípio da equidade para atenuar as desigualdades sociais, o combate a todas as formas de preconceito e discriminação, a defesa da democracia e ao Estado de Direito, o respeito ao patrimônio público, a forma contemporânea de lidar com o público e o privado e o empoderamento de participação da sociedade civil nos espaços de gestão, de modo a garantir a igualdade de oportunidades.

Baseada no ideal de humanismo que demarcou a transição dos séculos XX ao XXI, a ética da identidade se constitui a partir da estética e da política no reconhecimento da própria identidade e a de outrem, no âmbito do aprender a ser, complementando o domínio estético do aprender a fazer e a política do aprender a conhecer e a conviver. Tem por finalidade a formação para a autonomia, de pessoas responsáveis e solidárias. 
O currículo que destaca as competências de caráter geral em substituição às disciplinas isoladas e conteúdos específicos preconiza a capacidade de aprender como passaporte para a constituição da identidade autônoma. De acordo com as diretrizes curriculares do PCN de 1999 (p. 87), a seleção dos conteúdos deve estar de acordo com as múltiplas interações das disciplinas do currículo, com abertura e sensibilidade para identificar os contextos de vida social e pessoal, estabelecendo uma relação ativa entre o/a estudante e o objeto do conhecimento. Deve desenvolver a capacidade de relacionar o aprendido com o observado, a teoria com suas consequências e aplicação prática.

Em relação aos conteúdos dos currículos do Ensino Médio, as Diretrizes Curriculares Nacionais indicam como orientação sua (re)significação como meio para a constituição de competências e valores, distanciando-se do tratamento enciclopédico, de modo a propiciar formas coletivas de construção do conhecimento. Sugere a organização dos conteúdos em estudos ou áreas interdisciplinares e projetos que propiciem a visão orgânica do conhecimento e o diálogo permanente entre as diferentes áreas do saber. Recomenda também que estejam contextualizados para dar significado ao aprendido e estimular 0 protagonismo e a autonomia intelectual do/a estudante. (BRASIL, 1999, p, 87-88)

Prosseguindo, o documento refere que contextualizar o conteúdo significa reconhecer que todo conhecimento envolve uma relação entre sujeito e objeto. A mobilização das classes estudantis para estabelecer uma relação de reciprocidade entre o sujeito e o objeto constitui a efetivação das competências de superação da passividade nos processos de aprendizagem, a ponte entre a teoria e a prática.

Quando se recomenda a contextualização como princípio de organização curricular, o que se pretende é facilitar a aplicação da experiência escolar para a compreensão da experiência pessoal em níveis mais sistemáticos e abstratos e o aproveitamento da experiência pessoal para facilitar o processo de concreção dos conhecimentos abstratos que a escola trabalha (BRASIL, 1999, p, 73).

Em termos de contextualização, a base nacional comum deve contemplar conteúdos que garantam a formação geral prevista pela LDB voltada ao exercício da cidadania e habilitação para o trabalho, pela constituição de saberes integrados à ciência e à tecnologia. Na área das ciências humanas, a filosofia é 
citada na interdisciplinaridade dos currículos para a constituição da cidadania, direcionada ao desenvolvimento de competências. Tem por finalidade analisar os fundamentos epistemológicos do conhecimento e discutir acerca dos referenciais axiológicos que compreendem a vida em sociedade no campo da ética, da política e da estética. Sua importância aparece também na busca do entendimento sobre o ser e os elementos afetivos, sociais e culturais que constituem a identidade individual e coletiva.

Tendo em vista que o currículo não traduz uma realidade pronta e tangível, a avaliação torna-se o mecanismo indispensável para monitorar a ação educativa, exigindo que o eixo da flexibilidade e o eixo da avaliação sejam complementares. Currículos flexíveis requerem um processo constante de vigilância sobre a eficácia da relação teoria e prática, com abertura para o diálogo com outros saberes a fim de agregar novos conhecimentos. É na perspectiva de assegurar o tratamento interdisciplinar e contextualizado que os conhecimentos de filosofia retornam para reforçar o campo das humanidades em contraponto à formação instrumental técnico-científica.

\section{Conclusões sobre o Ensino de Filosofia}

A legislação brasileira reconhece o sentido histórico da atividade filosófica, enfatizando a competência da filosofia em promover, sistematicamente, as condições indispensáveis para a formação da cidadania plena. "[...] o pensamento filosófico resiste precisamente porque não abandona seu motivo originário" (BRASIL, 1999, p. 328). Destarte, a competência explicativa torna a filosofia fértil na geração de novos saberes. Embora definindo para a filosofia a tarefa que the cabe no contexto educacional, a legislação afirma que todos os conhecimentos, disciplinas

e componentes curriculares da Educação Básica são igualmente necessários à formação cidadã.

Entretanto, a legislação da década de 1990 destina a interdisciplinaridade e a contextualização como função primordial para a filosofia no Ensino Médio. Dimensionar o recorte dos conteúdos mínimos não é tarefa fácil diante do vasto universo dos conhecimentos filosóficos, a começar pela definição de critérios para 
a escolha das teorias prioritárias, conceituar o que é filosofia que a priori constitui-se num problema filosófico e entender os pressupostos da formação de cidadania.

No Ensino Médio, a filosofia não deve ser tratada segundo os cânones acadêmicos nem ao nível das crenças do senso comum. Por sua natureza reflexiva precisa estar fundamentada em boas razões e argumentos consistentes. É na reconstrução racional do exame analítico que a filosofia se volta para as competências cognitivas, linguísticas e de ação, em conteúdos relacionados com a lógica, a teoria do conhecimento, a epistemologia e todas as elaborações filosóficas que buscam explicar teoricamente um saber pré-teórico adquirido num dado sistema de regras.

Outra competência requisitada da filosofia é a crítica necessária para reconhecer as inconsistências teóricas e as ideologias inerentes à intencionalidade que permeia os currículos escolares e suas consequências práticas. "A Filosofia deve auxiliar o aluno do Ensino Médio a tornar temático o que está implícito e questionar o que parece óbvio" (BRASIL, 1999, p. 333). Nucleada nos valores do respeito ao bem comum e da consciência social, democrática, solidária e tolerante prevista pelas diretrizes a todas as disciplinas do currículo, as dimensões da ética, da estética e da política devem contemplar o ethos da atividade filosófica.

Do ponto de vista da estética, a cidadania traduz a fluência da expressão subjetiva e a livre aceitação da diferença, a capacidade de conhecer-se a si mesmo e a sensibilidade. Na perspectiva ética, a liberdade é tomada como condição de cidadania, devendo ser entendida como consciência e atitude de respeito universal, o ethos da identidade autônoma. E no âmbito da política, a cidadania pressupõe o reconhecimento dos direitos humanos, a prática da igualdade de acesso aos bens naturais e culturais, tolerância e protagonismo na Iuta pela sociedade democrática, na consciência de direitos e deveres e justiça equânime, o ethos de participação democrática (BRASIL, 1999, p. 332).

Por conseguinte, os três ethos se entrecruzam na medida em que cada um deles implica e corrige os outros. Funcionando como referências ideais, os ethos citados anteriormente servem ao propósito de explicitar os critérios políticos e 
axiológicos destes Parâmetros Curriculares, resgatando as concepções de base da reforma curricular.

Dentre as competências e habilidades, O PCN que antecedeu a obrigatoriedade da filosofia no Ensino Médio, em 2008, já delimitou especificidades próprias da abordagem disciplinar, incluindo os três grandes eixos de representação e comunicação, investigação e compreensão e contextualização sociocultural. No eixo de representação e comunicação o PCN previa como objetivos: "Ler textos filosóficos de modo significativo"; "Ler, de modo filosófico, textos de diferentes estruturas e registros"; "Elaborar por escrito o que foi apropriado de modo reflexivo e debater, tomando uma posição, defendendo-a argumentativamente e mudando de posição face a argumentos mais consistentes". No eixo de investigação e compreensão o documento determina como objetivo "Articular conhecimentos filosóficos e diferentes conteúdos e modos discursivos nas Ciências Naturais e Humanas, nas Artes e em outras produções culturais". Por fim, no eixo contextualização sociocultural consta como objetivo "Contextualizar conhecimentos filosóficos, tanto no plano de sua origem específica, quanto em outros planos: o pessoal-biográfico; o entorno sócio-político, histórico e cultural; o horizonte da sociedade científico-tecnológica" (BRASIL, 1999, p. 349).

Habilidades de leitura, interpretação e escrita, de análise e sistematização são esperadas do ensino de filosofia para fortalecer a integração entre as demais áreas cognitivas. O reconhecimento das diferentes dimensões e perspectivas teóricas e discursivas é tomado para exercitar a capacidade de problematização, leitura significativa, problematização, interpretação e sistematização rigorosa. A visão de conjunto e as especificidades da filosofia de articular teoria e prática foram consideradas na reforma curricular para auxiliar na contextualização e na interdisciplinaridade do Ensino Médio voltado à formação cidadã. 


\section{Referências bibliográficas}

BRASIL. [Lei Darcy Ribeiro (1996)] LDB: Lei de diretrizes e bases da educação nacional [recurso eletrônico]: Lei $n^{\circ}$ 9.394/96, de 20 de dezembro de 1996, que estabelece as diretrizes e bases da educação nacional. - 9.ed. - Brasília: Câmara dos Deputados, Edições Câmara: 2014. Disponível em:

$<$ https://www.google.com.br/search?q=LDB\&oq=LDB\&aqs=chrome..69i57j69i60l2.263 7j0j7\&sourceid $=$ chrome\&es_sm $=122 \&$ ie $=U T F-$

$8 \# q=L D B+C a m a r a+d o s+d e p u t a d o s+2014>$ Acesso em 14/07/15

BRASIL. Ministério da Educação. Secretaria de Educação Média e Tecnológica. Parâmetros Curriculares Nacionais: ensino médio. Brasília: MEC, 1999. 